UNIVERSIDADE DE BRASILIA - UNB

FACULDADE DE CIÊNCIAS DA SAÚDE

NÚCLEO DE ESTUDOS EM EDUCAÇÃO E PROMOÇÃO DA SAÚDE - NESPROM CENTRO DE ESTUDOS AVANÇADOS MULTIDISCIPINAR - CEAM

CURSO DE ESPECIALIZAÇÃO EM EDUCAÇÃO E PROMOÇÃO DA SAÚDE

Flávia Roberta Paes Vasconcelos

\title{
O ENSINO ÉTICO E HUMANIZADO NA RESIDÊNCIA DE CIRURGIA GERAL
}

PROFESSORA MSC. CAROLINA CONCEIÇÃO PRADO

BRASILIA, 
UNIVERSIDADE DE BRASILIA - UNB

FACULDADE DE CIÊNCIAS DA SAÚDE

NÚCLEO DE ESTUDOS EM EDUCAÇÃO E PROMOÇÃO DA SAÚDE - NESPROM CENTRO DE ESTUDOS AVANÇADOS MULTIDISCIPINAR - CEAM

CURSO DE ESPECIALIZAÇÃO EM EDUCAÇÃO E PROMOÇÃO DA SAÚDE

Flávia Roberta Paes Vasconcelos

\section{O ENSINO ÉTICO E HUMANIZADO NA RESIDÊNCIA DE CIRURGIA GERAL}

Trabalho de Conclusão de Curso - TCC Apresentado para a Banca Examinadora do Curso de Educação e Promoção da Saúde da Universidade de Brasília, como exigência parcial da obtenção do grau de especialista em Educação e Promoção da Saúde.

Professora: Msc. Carolina C. Prado

BRASILIA, 


\section{RESUMO}

Os temas da ética, bioética e humanização tem se tornado alvo de palpitantes discussões na Educação Médica em virtude da mudança de conceitos vigentes na sociedade contemporânea. Nesse atual contexto, onde se inclui a globalização da informação e do desenvolvimento técnico-científico, é fato comum a exigência da aprendizagem das mais diversas competências a fim de que haja integração no exercício de um dado "saber-fazer" profissional. Essa multiplicidade da demanda social atual interfere diretamente no contexto da discussão curricular e formação médica com o objetivo de produzir um profissional capacitado tecnicamente, mas também, um cidadão crítico e autônomo, capaz de agir nos diversos níveis de atenção à saúde. Sendo assim, este estudo visa, através de pesquisa qualitativa, por meio de revisão bibliográfica, fazer uma reflexão sobre a atual formação dos cirurgiões e ratificar a importância da inclusão de preceitos morais, éticos e de humanização no currículo da Residência Médica em Cirurgia Geral. Conclui-se que o Programa de Residência Médica em Cirurgia Geral possui uma lacuna em sua grade curricular no tocante à temática da ética e da humanização e, tendo em vista serem esses temas de grande relevância na formação de qualidade para, não só esta especialidade, mas toda e qualquer área de atuação médica, sugere-se a inclusão desses preceitos no currículo oficial deste Programa.

Palavras-chave: Educação Médica, Ética, Humanização, Residência Médica em Cirurgia Geral 


\section{SUMÁRIO}

RESUMO

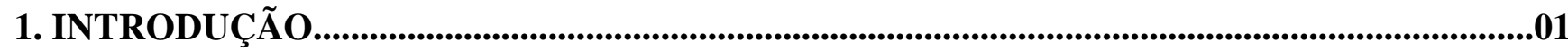

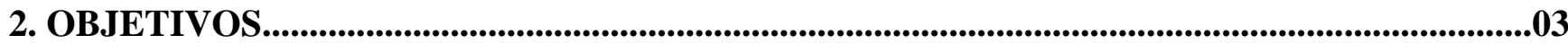

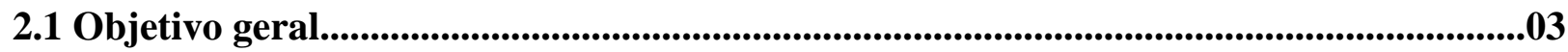

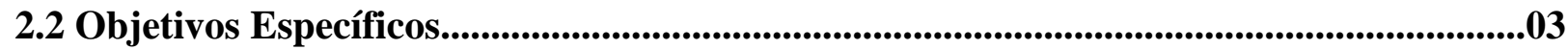

3. ÉTICA E HUMANIZAÇÃO NO ENSINO MÉDICO...........................................................04

4. METODOLOGIA.............................................................................................................................................07

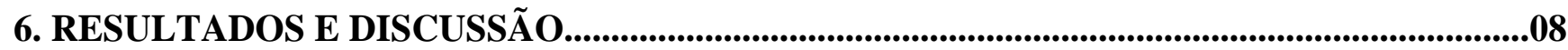

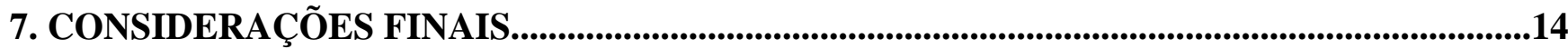

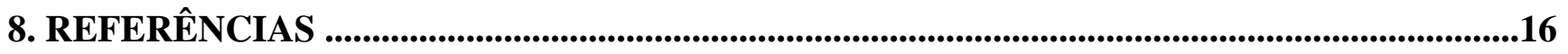




\section{INTRODUÇÃO}

A história das escolas médicas no Brasil se confunde com a própria história da Medicina no país e teve como fato marcante em sua idealização, a vinda da Família Real em 1808. Na comitiva real portuguesa estava o Dr José Correia Picanço, cirurgião-mor do Reino, formado pela Escola Médica de Montpelier e foi ele quem ajudou D. João VI a inaugurar em 18 de fevereiro daquele mesmo ano, em Salvador, a primeira Escola Médica do Brasil, a Escola Anatômico-Cirúrgica e Médica da Bahia, hoje, Faculdade de Medicina da Universidade Federal da Bahia. Nove meses depois, no Rio de Janeiro, implantou a Escola de Anatomia, Medicina e Cirurgia, mais tarde conhecida como Universidade do Brasil e atualmente como Escola de Medicina da Universidade Federal do Rio de Janeiro (SANTOS 2009).

Por volta de 1948, havia no país, a preocupação com a formalização do treinamento da cirurgia após a graduação. Assim, o Prof. Mariano de Andrade no Hospital dos Servidores do Estado do Rio de Janeiro e o Prof. Alípio Correa Neto no Hospital de Clínicas em São Paulo idealizaram os primeiros programas de Residência Médica em Cirurgia no Brasil.

Em 05 de setembro de 1977 ao assinar o decreto 80.281, o Presidente da República, General Ernesto Geisel sancionou a criação da Residência Médica e assim a definiu como "modalidade de ensino de pós-graduação destinada a médicos sob forma de curso de especialização caracterizada por treinamento em serviço funcionando em instituições de saúde, universitárias ou não, sob a orientação de profissionais médicos de elevada qualificação ética e profissional", a qual confere ao médico, após seu término, o certificado de Especialista na área cursada. (NUNES, 2003)

A Residência Médica (RM) obedece a leis e regulamentações próprias e só pode receber essa designação o programa de treinamento credenciado pelo Ministério da Educação (MEC). Ela está diretamente subordinada à Comissão Nacional de Residência Médica (CNRM) que obedece à Secretaria de Educação Superior (SESu). Essa, por sua vez, está ligada ao Departamento de Assuntos Universitários do Ministério da Educação.

Na definição do Colégio Brasileiro de Cirurgiões (CBC):

"o Cirurgião Geral é o médico com o conhecimento da doença, do diagnóstico e do tratamento 
das enfermidades tratáveis por procedimento cirúrgico, principalmente no que concerne às urgências. Sua formação deve prepará-lo para a execução das intervenções básicas de todas as especialidades" (CBC, 1974. p.68).

O objetivo da Residência Médica em Cirurgia Geral é oferecer ao residente, o treinamento em hospital com condições adequadas para que o futuro cirurgião possa oferecer à sociedade o padrão máximo de excelência: um profissional bem treinado e capaz de pôr em prática, nos grandes centros e fora deles, de forma humanizada, as habilidades adquiridas com as mais diversas tecnologias.

Ser um cirurgião requer capacidade de liderança e de tomar decisões em tempo, muitas vezes, curto, além de exigir grande controle emocional, autoconfiança, tenacidade e paciência, e mais do que tudo isso, total disponibilidade para dedicar-se ao seu paciente.

Atualmente, a figura do cirurgião eminentemente técnico, resolutivo, agressivo e arrogante está sendo substituída por um profissional de convívio multidisciplinar, muito cobrado por seus resultados e altamente especializado, com uma formação que vem se tornando, a cada dia, um desafio.

Ensinar cirurgia depende de muitos mecanismos formais (atividades em sala de aula, discussões de casos à beira do leito, conferências, seminários) como também informais (conversas fora do ambiente hospitalar e, até mesmo, confidências) e, muitos autores consideram a educação informal como importante instrumento didático neste contexto, principalmente, no que concerne à ética, a humanização e o equilíbrio psicossocial do aprendiz, a qual entende-se que deve ser formalizada, com a inclusão de temas como filosofia, ética e comportamento nas discussões diárias.

Sendo assim, este estudo visa, por meio de revisão bibliográfica, fazer uma reflexão sobre a atual formação dos cirurgiões e ratificar a importância da inclusão de preceitos morais, éticos e da humanização no currículo da Residência Médica em Cirurgia Geral. 


\section{OBJETIVO}

\section{OBJETIVO GERAL:}

Refletir sobre a atual formação dos cirurgiões e ratificar a importância da inclusão de preceitos morais, éticos e da humanização no currículo da Residência Médica em Cirurgia Geral.

\section{OBJETIVOS ESPECÍFICOS:}

- Analisar o currículo da Residência Médica em Cirurgia Geral;

- Investigar a relevância da inclusão dos preceitos morais, éticos e de humanização na formação do Cirurgião Geral;

- Traçar estratégias para a inclusão desses preceitos no currículo da Residência Médica em Cirurgia Geral 


\section{ÉTICA E HUMANIZAÇÃO NO ENSINO MÉDICO}

Os temas da ética, bioética e humanização tem se tornado alvo de palpitantes discussões na Educação Médica em virtude da mudança de conceitos vigente na sociedade contemporânea (FERREIRA, 2004; REGO; PALÁCIOS; SCHRAMM, 2004).

Nesse atual contexto, onde se inclui a globalização da informação e do desenvolvimento técnico-científico, é fato comum a exigência da aprendizagem das mais diversas competências a fim de que haja integração no exercício de um dado "saber-fazer" profissional (SILVA FILHO, 1994; PERRENOUD, 1999).

A multiplicidade da demanda social atual interfere diretamente no contexto da discussão curricular e formação médica com o objetivo de produzir um profissional capacitado tecnicamente, mas também, um cidadão crítico e autônomo, capaz de agir nos diversos níveis de atenção à saúde (REGO; GOMES; SIQUEIRABATISTA, 2008).

Ao longo de mais de três décadas, a disciplina Ética adquiriu diferentes conotações na prática médica, podendo-se perceber variações do tema, ainda que não tenha deixado de se orientar para a discussão da moralidade dos atos humanos.

O termo ética tem vários conceitos e pode ser compreendido como o saber que investiga os juízos sobre os atos qualificados como bons ou maus (ABBAGNANO, 2003; LALANDE, 1983).

Em geral, a ética pode ser diferenciada da moral por ser um saber filosófico, enquanto a moral se refere a condutas vivenciadas pela sociedade em seu cotidiano. (REGO, PALÁCIOS, SCHRAMM, 2004).

De maneira geral, todos sabemos que os indivíduos são capazes de realizar julgamentos morais, porém é na capacidade de interação destes indivíduos com o seu meio social que se avalia o resultado desta interface, bem como se avalia se este resultado é benéfico para ambos. Isto posto, é fácil correlacionar a responsabilidade do Ensino Médico e, mais especificamente no nível de especialização médica (como no Programa de Residência Médica em Cirurgia Geral) em estimular o estudo do tema, tendo em vista a sua missão em formar bons profissionais não só no nível técnico, mas também com base moral e ética.

A importância desta atribuição é reconhecida pelas próprias diretrizes curriculares nacionais, embora, em geral, as instituições de ensino superior tratem a 
formação moral como se ela ocorresse como consequência da formação técnica.

Não basta à Ética, a mera definição de conceitos e normatizações de condutas, como realizado, há muito, pela disciplina de Deontologia Médica. Para sua assimilação no cotidiano da prática médica, é preciso criar condições de autonomia para o seu efetivo exercício; é preciso agir como educadores, possibilitando discussão do que seja competência moral.

Já humanizar diz respeito à adquirir a forma humana, tornar-se benévolo, ameno, tolerável; humanar-se; tornar-se mais sociável, mais tratável; civilizar-se, socializar-se (REGO, 2008).

Com base nesta caracterização, observa-se que a questão da humanização tem relação com a própria construção do conceito de homem na tradição ocidental, a qual pode ser vislumbrada desde suas origens, na cultura grega, com as epopéias homéricas.

Neste contexto, pode-se argumentar que todo o esforço do pensamento grego diz respeito à temática HOMEM e que, desde a poesia, passando pela filosofia e chegando à Medicina, o que sempre se destacou foi a figura humana.

No campo da atenção em saúde, o termo humanização tem sido utilizado com diferentes significados e entendimentos.

Atualmente, o conceito tem por objetivo associar a assistência em saúde ao acolhimento e melhoria no ambiente de atendimento e de trabalho. Deve-se, então, promover uma mudança na gestão das instituições de saúde e assumir-se essa postura humanizada de assistência, valorizando o respeito ao cidadão usuário.

Diante dessa nova visão, houve a necessidade de redefinição dos modos de construção das políticas públicas em saúde. E nesse cenário, o Ministério da Saúde lançou, em 1994, a Política Nacional de Humanização (PNH), Humaniza SUS, com a proposta de enfrentar o desafio de retomar os princípios do SUS. E, um dos grandes problemas a serem solucionados é a sensibilização dos profissionais da área.

Nesta perspectiva, torna-se importante a incorporação, pelos diferentes atores envolvidos no processo de produção da saúde, de atitudes tais como acolhimento, solidariedade e compaixão, que são os elementos fundamentais para a construção de boas relações interpessoais.

Não tem sido fácil, o estímulo aos debates sobre a humanização nos processos de reformulação curricular, de modo a permitir a formação de profissionais com uma visão mais abrangente do processo de promoção, prevenção e assistência à 
saúde (COTTA et al., 2004).

Como fazê-lo é uma difícil questão. Certamente, não é tarefa simples que se possa resolver com mudanças pontuais na metodologia de ensino ou aumento de disciplinas nos currículos da Residência Médica em Cirurgia. A certeza que temos é de que educar é formar e, em sendo assim, o papel do educador e das instituições de ensino, não é só o de informar, tampouco o de transformar experiência educativa em puro treinamento técnico (FREIRE, 2003).

Reconhece-se, que, para a garantia da integralidade do cuidado, deve-se permitir o desenvolvimento de um trabalhador ativo e capaz de aprender a aprender e, mais do que aprender a fazer, deve aprender a conviver e aprender a ser (FERNANDES, et al., 2003). Portanto, as abordagens pedagógicas progressistas de ensinoaprendizagem vêm se construindo com ferramentas de reintegração das habilidades perdidas pelo médico em sua trajetória histórica de formação, permitindo alcançar como resultado a conquista de profissionais com competências humanas, éticas, políticas e técnicas, dotados de conhecimento técnico sim, mas também responsabilidade e sensibilidade para as questões da vida e das pessoas, com a capacidade de interagir em contextos de incertezas e complexidades, como os da medicina atual (ZANOLLI, 2004).

Desta forma, percebe-se a relevância dos termos deste debate que envolve ética, humanização e educação, os quais podem ser pensados, conjuntamente, de forma articulada e complexa, no âmbito da formação médica. E, é, neste sentido, que se precisa reconhecer que um dos principais aspectos a considerar é que também cabe ao sistema educacional a responsabilidade de contribuir com o processo de desenvolvimento da competência moral e ética de um indivíduo. Para tanto, não importam apenas as abordagens pedagógicas próprias, mas também as oportunidades para o exercício da autonomia dos aprendizes e da prática do diálogo, os quais devem iniciar-se durante a graduação, se estender durante a pós-graduação e manter-se como um processo de educação continuada após a inserção deste profissional no mercado de trabalho (LIND, 2006; SCHILLINGER, 2006). 


\section{METODOLOGIA}

Considerando todos os aspectos destacados e com o objetivo de refletir sobre a atual formação dos cirurgiões e ratificar a importância da inclusão de preceitos morais, éticos e da humanização no currículo da Residência Médica em Cirurgia Geral, utilizouse a metodologia de pesquisa qualitativa que tem por desígnio proporcionar maior proximidade com o problema, com vista a torná-lo mais claro. “O planejamento para este tipo de trabalho é bastante flexível, de modo que possibilite a consideração dos mais variados aspectos relativos ao fato estudado” (GIL, 2002, p. 41).

Tal procedimento metodológico permitiu a avaliação e comparação de dados de pesquisas realizadas recentemente.

Assim, para a elaboração deste estudo, pesquisou-se artigos científicos no portal Scielo Brasil, publicados no período de 2000 a 2010, sobre o Ensino Médico Ético e Humanizado. Para a seleção dos artigos optou-se por aqueles que cruzassem duas ou mais das seguintes palavras-chaves: ética, humanização, residência médica em cirurgia geral, educação em saúde, ensino médico. Desta forma, dez artigos científicos foram selecionados para revisão bibliográfica.

As análises obtidas foram transcritas na forma de texto e tabelas. Tais resultados seguem no próximo capítulo. 


\section{RESULTADOS E DISCUSSÃO}

Os resultados obtidos estão descritos na tabela 01 .

Tabela 01 - Resultados da revisão bibliográfica (2000-2010).

\begin{tabular}{|c|c|c|c|}
\hline Autores & Título & Palavras-chaves & Ano \\
\hline JESUS, L.E & Ensinar cirurgia: como e pra quem? & $\begin{array}{l}\text { Educação médica; residência em } \\
\text { cirurgia geral }\end{array}$ & 2008 \\
\hline SANTOS, E.G & $\begin{array}{l}\text { Residência Médica em Cirurgia } \\
\text { Geral no Brasil - muito distante da } \\
\text { realidade profissional }\end{array}$ & $\begin{array}{l}\text { Educação médica; residência em } \\
\text { cirurgia geral }\end{array}$ & 2009 \\
\hline $\begin{array}{l}\text { REGO, S; } \\
\text { GOMES, A.P.; } \\
\text { SIQUEIRA- } \\
\text { BATISTA, R. }\end{array}$ & $\begin{array}{l}\text { Bioética e humanização como tema } \\
\text { transversais na formação médica }\end{array}$ & $\begin{array}{l}\text { Educação médica, ética, } \\
\text { humanização }\end{array}$ & 2008 \\
\hline SILVA, A.L & Cirurgia Geral e o sistema de saúde & $\begin{array}{l}\text { Residência em cirurgia geral, } \\
\text { SUS }\end{array}$ & 2002 \\
\hline $\begin{array}{l}\text { NOVAES, } \\
\text { M.R.G; et. al. }\end{array}$ & $\begin{array}{l}\text { Inserção dos temas de humanidades } \\
\text { e ética em currículo médico } \\
\text { integrado em escola pública no } \\
\text { Distrito Federal, Brasil }\end{array}$ & $\begin{array}{l}\text { Humanização em saúde, ensino } \\
\text { médico }\end{array}$ & 2009 \\
\hline STRAUSS, F. & $\begin{array}{l}\text { Entre o ensino, a pesquisa e a } \\
\text { assistência médica: um estudo de } \\
\text { caso }\end{array}$ & $\begin{array}{l}\text { Ensino médico, educação em } \\
\text { saúde }\end{array}$ & 2009 \\
\hline $\begin{array}{l}\text { BULCÃO, L.G.; } \\
\text { EL KAREH, } \\
\text { A.C.; SAYD, J. }\end{array}$ & $\begin{array}{l}\text { Ciência e Ensino Médico no Brasil } \\
\text { (1930-1950) }\end{array}$ & $\begin{array}{l}\text { Educação médica, ensino } \\
\text { médico }\end{array}$ & 2007 \\
\hline $\begin{array}{l}\text { BULCÃO, L.G.; } \\
\text { SAYD, J.D. }\end{array}$ & $\begin{array}{l}\text { As razões da escola médica: sobre } \\
\text { os professores e seus valores. Os } \\
\text { valores dos médicos e os impasses } \\
\text { da escola médica }\end{array}$ & $\begin{array}{l}\text { Educação médica, ensino } \\
\text { médico }\end{array}$ & 2003 \\
\hline SILVA, M. R.B. & O ensino médico em debate & $\begin{array}{l}\text { Educação médica, ensino } \\
\text { médico }\end{array}$ & 2002 \\
\hline NUNES, M.P.T & $\begin{array}{l}\text { Residência Médica no Brasil: } \\
\text { situação atual e perspectivas }\end{array}$ & $\begin{array}{l}\text { Educação médica, residência } \\
\text { medica }\end{array}$ & 2003 \\
\hline
\end{tabular}


Jesus (2008) descreve a atual demanda na formação do cirurgião engajada com a demanda social e demonstra que são muitos os fatores que contribuem para a necessidade de mudança de paradigmas na educação médica em cirurgia, baseado, inclusive em estereótipos de personalidade do indivíduo que exerce a função de cirurgião, o qual deve ser reconhecido como um indivíduo que está inserido num contexto social de quem se cobra conduta técnica impecável, mas também anseia por modelo profissional mais humano e ético.

Este é o atual consenso com relação à formação médica, onde o maior empenho está na discussão na formalização dos conceitos de ética e humanização na grade curricular.

Já Santos (2009) ordena fatos históricos da atuação médica no país, bem como da implementação do ensino universitário em medicina e alerta para a necessidade de uma formação ampla e profunda para o ensino da Cirurgia Geral a fim de que se cumpra o objetivo de garantir à sociedade a formação de um profissional capacitado técnica e humanitariamente.

"O Cirurgião Geral amplamente treinado possui grande valor... treinado dessa forma ele pode prestar cuidados totais ao paciente na grande maioria das doenças que requerem tratamento cirúrgico..." (SANTOS, 2009. p. 274)

Como responsáveis e partes integrantes da formação de futuros cirurgiões, é dever do educador incentivá-los a desenvolver e cultivar o exercício da ciência e a arte da cirurgia com competência, qualidade e dignidade (SANTOS 2009). Assim, o futuro desta especialidade está na garantia da evolução da formação durante a graduação e na especialização.

Rego; Gomes; Siqueira-Batista (2008) traçam relação da pluraridade social atual com a nova exigência dos novos conceitos do "saber-fazer" em saúde, mais especificamente com relação aos médicos e faz correlação dos termos ética, humanização e educação os quais podem ser pensados, conjuntamente, de forma articulada e complexa, no âmbito da formação médica, de modo a constituírem espaços para uma abordagem interdisciplinar.

O artigo corrobora e ratifica o pensamento comum na "nova educação médica”, onde o foco é a pessoa e, não pura e simplesmente, a informação teórica, mesclando as temáticas: educação, ética e humanização se chegará a um profissional 
completo e digno de atuar com essa pluralidade social.

Segundo Silva, A.L. (2002), o exercício da cirurgia no mundo contemporâneo pode ser dividido em: operações gerais e especializadas. As primeiras estão ligadas à periferia dos grandes centros e a um volume de paciente que não tem acesso fácil, ágil e eficiente ao sistema de saúde, enquanto as outras se caracterizam pelo envolvimento de um ou mais especialistas para resolver um só problema. Mas, é necessário se estabelecer princípios para hierarquizar o sistema. Como fazê-lo, então?

A escola médica e o sistema de saúde têm que se dividir em duas partes distintas: na primeira etapa, a escola tem que formar médicos voltados para o mais prevalente e o comum, há que se prestigiar e remunerar muito bem o profissional que trabalha e desenvolve o sistema de atendimento básico. Na segunda etapa, a escola e o sistema têm de investir no especialista, prestigiando a residência e a reciclagem. O hospital universitário é uma empresa de prestação de serviço e um instrumento de ensino da faculdade para preparar o médico e o especialista. A solução não depende somente de dinheiro, mas de um ato de coragem do Ministério da Educação em reformular o ensino medico básico adaptado a cada região e ao Ministério da Saúde enfrentar as opiniões contrárias ou interesses dirigidos, prestigiando o homem que atende as áreas médicas de que a população tanto carece.

O estudo de Novaes; et. al. (2009) trata-se de um estudo de coorte e documental que teve como objetivo analisar a inserção da ética e humanização no currículo do curso de Medicina da Escola Superior de Ciências da Saúde no Distrito Federal e que concluiu que o projeto pedagógico do curso está contemplando os temas de forma abrangente, com a exceção da cadeira de Cirurgia Geral, a qual não possui em seu conteúdo o estudo dos temas.

É um estudo importante para a discussão da temática a fim de se vislumbrar novas perspectivas na reformulação curricular no ensino médico e veio ratificar o modo tecnicista da formação cirúrgica prevalente, em detrimento do estímulo ao debate ético e humanitário da assistência.

Com relação ao artigo de Strauss (2009), têm-se como principal discussão as inúmeras transformações pelas quais têm passado as atividades de ensino e assistência médicas a partir da criação da faculdade de medicina do Rio de Janeiro em 1808. O autor descreve que de 1830 a 1880 prevaleceu o modelo anátomo-clínico da escola francesa. Entretanto, em 1882, a reforma de Sabóia, de inspiração germânica, trouxe um novo ideal de ensino prático e livre. Somente em 1978 é que houve a 
inauguração do Hospital Universitário Clementino Fraga Filho e nessa mesma época surgiu a epidemiologia clínica, área de importância extrema em todos os setores da medicina. Os programas de pós-graduação também foram desenvolvidos concomitantemente, dando um impulso às atividades de pesquisa, porém com certa dificuldade, já que havia falta de financiamentos, recursos, infra-estrutura, estímulo e preparo dos docentes. A década de 1990 forneceu condições mais atraentes e estimulantes para a pesquisa e, ainda que de maneira incipiente, integra a instituição e caminha paralelamente ao ensino e à assistência médica.

Porém, ainda há obstáculos a serem vencidos e talvez, o mais importante deles é a desvalorização dos seus professores, como os baixos salários, a falta de políticas institucionais além de desequilíbrio da divisão do corpo docente entre o ensino, a assistência e a pesquisa. Por considerar que estamos numa nova etapa a ser ultrapassada na história do ensino medico do país, devemos conhecer as experiências passadas e reconhecer nelas uma forma de renovação, corrigindo-se os pontos divergentes a fim de se melhorar os resultados futuros.

Bulcão; El Kareh; Sayd (2007) abordam o papel da ciência e seu impacto na elaboração dos cursos médicos entre 1930 a 1950 e teve como objetivo evidenciar que a conformação curricular destas escolas foi constituída com base no contexto sociopolítico e econômico da época, um momento de forte crescimento industrial e urbano.

De fundamental importância no contexto descrito pelos autores, é o papel da Fundação Rockefeller, a qual foi responsável pela instituição dos padrões norteamericanos de valores culturais e científicos no Brasil, incorporando a ciência como principal método de trabalho e ideologia na conformação curricular das escolas médicas, o que fortaleceu a "especialização" da Medicina, valorizando o mercado privado da atividade médica (BULCÃO; EL KAREH; SAYD, 2007).

Talvez esse tenha sido o maior estímulo à informação técnico-científica pura como base da formação médica que incorporou esse estigma de educação formalizada no país e que é tão difícil de ser contestada e transformada.

Ao realizar seu trabalho científico, BULCÃO; SAYD (2003) tiveram como objetivo analisar o comportamento de professores médicos de uma escola pública do Rio de Janeiro, na tentativa de entender o chamado “currículo oculto” do curso médico, tendo em vista a estreita relação dos valores do professor com a formação de seus estudantes. Foram entrevistados docentes de várias especialidades (clínica médica, 
cardiologia, nefrologia, otorrinolaringologia, cirurgia geral, cirurgia vascular, microbiologia, medicina do trabalho e saúde pública). Os cirurgiões docentes entrevistados valorizavam mais os aspectos relativos a técnica e habilidades, bem como a capacidade de resolução de problemas práticos. Em relação ao ensino, propriamente dito, os professores mostraram-se preocupados com a qualidade da formação médica no tocante à precariedade de recursos materiais e tecnológicos, além da desvalorização dos recursos humanos, o que, no seu entendimento, é o principal ponto de conflito no ensino médico.

Trata-se de mais um autor que descreve a essência de educação voltada para os assuntos técnicos dos cirurgiões, mas é um artigo importante porque demonstra a visão dos educadores e essa visão certamente influencia em seu trabalho docente. Professores desestimulados e eminentemente técnicos transmitem aos seus alunos esses sentimentos e assim, como haverá de se mudar paradigmas?

Já Silva, M.R.B. (2002) faz uma descrição histórica da formação das primeiras Faculdades de Medicina em São Paulo, Brasil, as quais almejavam ter caráter de exceção no país, com grade curricular diferenciada, valorizando a incorporação de modelo pedagógico baseado em ensino e pesquisa. Esperava-se que uma faculdade fosse local de produção de conhecimento científico, por meio da pesquisa experimental e desenhava-se nesses espaços, um perfil que se esperava imprimir à medicina paulista como um todo, perfil que conferisse ao campo médico personalidade própria e legitimidade no cenário nacional, ao mesmo tempo em que decisões do governo estadual também definiam as prioridades a serem atendidas pelas políticas de saúde.

A escola médica paulista imprimiu no país uma forma peculiar do ato de ensinar, privilegiando pesquisas científicas de vanguarda, com valorização da produção da ciência experimental, porém também esse fato desprivilegia a ciência humana, e assim, o estudo e formação das pessoas, inclusive nos aspectos sócio-culturais.

O artigo de Nunes (2003) posiciona a Residência Médica quanto a seu conceito como uma modalidade de formação de recursos humanos na área médica, a qual privilegia o ensino da prática clínica hospitalar e o treinamento profissional em serviço. A sua criação aconteceu há aproximadamente 60 anos e foi regulamentada há mais de 20 anos. Segundo a autora, a Residência Médica está consagrada como a melhor forma de inserção de profissionais médicos na vida profissional sob supervisão e de capacitação em uma especialidade. 
Porém, também reconhece uma série de particularidades que complicam o desenvolvimento deste programa e pontua os principais problemas que prejudicam sua evolução como sendo de aspectos de avaliação, demanda acesso e financiamento. Por fim, afirma que é urgente a necessidade de avaliar os programas em curso, envolvendo todos os seus atores, tais como as sociedades de especialistas, os conselhos de medicina e as escolas, num esforço para estabelecer critérios técnicos, éticos e de demanda, a fim de garantir a qualidade da formação (NUNES, 2003).

É um texto crítico que estimula o pensamento nos debates da filosofia do Programa de Residência Médica, que pode ser considerado o modelo de formação do especialista medico, mas que deve sofrer alguns ajustes para se adequar ao atual momento dos indivíduos, tanto no tocante aos próprios médicos aprendizes, como os cidadãos no geral.

Os artigos pesquisados nos demonstram bem o atual contexto da sociedade brasileira e mundial, a qual tem sido a base para a formação da demanda dos profissionais de saúde no país e pode-se bem observar que essa sociedade não mais aceita uma formação medica voltada pura e simplesmente para os aspectos técnicos do ato medico. Eles demonstram também a base histórica desse conceito, onde a formação acadêmica teve grande influência de padrões norte-americanos, onde se valorizava a educação voltada para padrões de pesquisa científica experimental, feitas em laboratórios, distanciando os profissionais das ciências humanas. 


\section{CONSIDERAÇÕES FINAIS}

Historicamente, o ensino médico no Brasil teve grande predomínio da formação técnica, em detrimento da voltada para as ciências humanas, tais como o ensino da ética e humanização.

Durante a graduação, há algum tempo, várias escolas médicas oficializaram disciplinas de humanização em seu currículo, porém as discussões sobre o tema possuem muitas particularidades e é comum se admitir grande dificuldade em integrar os temas humanísticos à prática da Medicina, pois os alunos os descrevem como dispensáveis e desinteressantes, em especial, na cadeira de Cirurgia Geral, onde os profissionais têm um perfil eminentemente, prático, que valorizam quase que exclusivamente as habilidades técnicas do ato médico.

Sabe-se que, informalmente, no chamado currículo oculto, os educadores inserem a temática com seus estudantes, na medida em que seu próprio comportamento, a posição diante dos problemas e sua postura com o cuidado dos pacientes são tidos como exemplo a ser ou não seguido pelos aprendizes.

Desta forma, o "currículo oculto" deve ser formalizado e a temática, amplamente discutida nas avaliações dos Programas de Especialização, a fim de que seja considerada parte integrante do conteúdo prático do treinamento.

Esta é a exigência da sociedade contemporânea, com sua atual revisão de valores e atitudes, onde os cidadãos cobram de seus médicos assistentes, competências múltiplas, tanto técnicas, quanto humanas e éticas e é este reconhecimento que garante ao Sistema Educacional uma forma de desenvolver e/ou aprimorar essa postura nos futuros cirurgiões.

Diante do exposto, conclui-se que o Programa de Residência Médica em Cirurgia Geral possui uma lacuna em sua grade curricular no tocante à temática da ética e da humanização e, tendo em vista serem esses temas de grande relevância na formação de qualidade para, não só esta especialidade, mas toda e qualquer área de atuação médica, sugere-se a inclusão desses preceitos no currículo oficial deste Programa.

É de fundamental importância que o ensino da ética e da humanização nas escolas médicas parta da conscientização dos temas em todos os focos que se dá o ato de aprender.

Com relação mais especificamente aos Programas de Residência Médica em 
Cirurgia Geral, que se trata do programa-base para as demais especialidades cirúrgicas, é preciso que os hospitais-escola desenvolvam esses temas no seu dia-a-dia, integrandoos com as disciplinas teóricas em sua grade curricular, numa real integração serviçoensino. 


\section{REFERÊNCIAS}

ABBAGNANO, N. Dicionário de filosofia. 4 ed. São Paulo: Martins Fontes; 2003.

BOLETIM INFORMATIVO DO COLÉGIO BRASILEIRO DE CIRURGIÔES. Jul-Agost-1974;68

BULCÃO, Lúcia Grando; SAYD, Jane Dutra. As razões da escola sobre os professores e seus valores. Os valores dos médicos e os impasses da escola médica. Rev. Saúde Coletiva. 2003, vol. 13, n. 1, pp. 11-38.

BULCÃO, Lúcia Grando; EL KAREH, Almir Chaiban; SAYD, Jane Dutra. Ciência e Ensino Médico no Brasil (1930-1950). História, Ciências, Saúde - Manguinhos, Rio de Janeiro, v.14, n.2, p.469-487, abr.-jun. 2007.

COTTA, R.M.M., PEREIRA, R.J., MAIA, T.M., MARQUES, E.S., FRANCESCHINI, S.C.C. Aprehensión y conocimiento de las directrices del SUS: un reto em la consolidación de la política de salud brasileña. Rev Agathos. 2004; 3: 16-23.

FERNANDES, J.D; FERREIRA, S.L.A; OLIVA, R; SANTOS, S. Diretrizes estratégicas para a implantação de uma nova proposta pedagógica na Escola de Enfermagem da Universidade da Federal da Bahia. Rev Enfermagem. 2003; 56(54): 392-5.

FERREIRA, N.S.C. Repensando e ressignificando a gestão democrática da educação na "cultura globalizada". Educ Soc. 2004; 25(89): 1227-49

FREIRE, P. Pedagogia da autonomia: saberes necessários à prática educativa. São Paulo: Paz e Terra; 2003.

GIL, Antônio Carlos. Como Elaborar Um Projeto de Pesquisa. 4. ed. - São Paulo: Atlas. 2002. p. 41- 42.

JESUS, Lisieux Eyer. Ensinar cirurgia: como e pra quem? Rev. Col. Bras. Cir. [online]. 2008, vol.35, n.2, pp. 136-140.

LALANDE, A. Vocabulaire tecnique et critique de la philosophie. 14 éd. Paris: Presses Universitaires de France; 1983.

LIND, G. La moral se puede enseñar: un manual de teoría y práctica de la formación moral y democrática. Ciudad del Mexico: Trillas; 2006.

NOVAES, Maria Rita Garbi; NOVAES, Luiz Carlos Garcez; GUILHEM, Dirce; 
LOLAS, Fernando; SILVEIRA, Carla; GUIOTTI, Murilo. Inserção dos temas de humanidades e ética em currículo médico integrado em escola pública do Distrito Federal, Brasil. Acta Bioethica [online]. 2009, vol.15, n.2, pp. 202-211.

NUNES, Maria do Patrocínio Tenório. Residência Médica no Brasil: situação atual e perspectivas. Cadernos ABEM. 2004; 1:30-32

PERRENOUD, P. Construir as competências desde a escola. Porto Alegre: Artmed; 1999.

REGO, S. A formação ética do médico: saindo da adolescência com a vida (dos outros) nas mãos. Rio de Janeiro: Fiocruz; 2008

REGO, S.; PALÁCIOS, M.; SCHRAMM, F.R. O ensino da Bioética nos Cursos de Graduação em Saúde. In: MARINS, J.J.N., REGO, S., LAMPERT, J.B., ARAÚJO, J.G.C., orgs. Educação médica em transformação: instrumentos para a construção de novas realidades. São Paulo: Hucitec/ABEM; 2004. p.165-185.

REGO, S.; GOMES, A. P.; SIQUEIRA-BATISTA, R. Bioética e humanização como temas transversais na formação médica. Rev. bras. educ. med. [online]. 2008, vol.32, n.4, pp. 482-491.

SANTOS, Elizabeth Gomes dos. Residência médica em cirurgia geral no Brasil - muito distante da realidade profissional. Rev. Col. Bras. Cir., [online]. 2009, vol.36, n.3, pp. 271-276.

SHILLINGER, M. Learning environment and moral development: how university education fosters moral judgment competence in Brazil and two German-speaking countries. Deutschland Aachen: Shaker; 2006.

SILVA, Alcino Lázaro. Cirurgia Geral e o Sistema de Saúde. Rev. Col. Bras. Cir. [online]. 2002, vol.29, n.5, p.I-II.

SILVA, Márcia Regina Barros de. O ensino médico em debate: São Paulo - 1890 a 1930. Hist., ciênc., saúde - Manguinhos. 2002, vol. 9, n.0, pp. 139-159

SILVA FILHO, H.P. O empresariado e a educação. In: FERRETI, C.J., et al. Novas tecnologias, trabalho e educação: um debate multidisciplinar. Petrópolis: Vozes; 1994.

SRAUSS, Francisco; LETA, Jacqueline. Entre o ensino, a pesquisa e a assistência médica: um estudo de caso. Hist., ciênc., saúde- Manguinhos. 2009, vol.16, n.4, pp. 1027-1043. 
ZANOLLI, M.B. Metodologias ativas de ensino-aprendizagem na área clínica. In: MARINS, J.J.N., REGO, S., LAMPERT, J.B., ARAÚJO, J.G.C., orgs. Educação médica em transformação: instrumentos para a construção de novas realidades. São Paulo: Hucitec/ABEM; 2004. 